\title{
O ensino de recreação: repensando algumas práticas
}

Edmilson Santos dos Santos ${ }^{1}$

\section{Resumo}

Este trabalho tem por objetivo analisar os pontos pelos quais os livros que sugerem atividades "práticas" em recreação ancoram-se para justificar determinados procedimentos e referendar determinadas práticas acadêmicas como sendo verdadeiras. Para isso, foram analisadas vinte e duas obras que tratam sobre recreação infantil. As estratégias utilizadas pela literatura de experimentação para constituir a verdade sobre a disciplina de Recreação estão vinculadas a uma separação nítida entre teoria e a prática, como realidades opostas, o reforço da heteronomia da criança e a simplificação da realidade a seus aspectos superficiais.

Palavras-chave: Recreação, Ensino, Lazer.

\begin{abstract}
Thispaper aims at analyzing the topics by which the books which suggest practical activities in recreation justify certain procedures and authorize certain academic practices as valid. To reach this result 22 books dealing with child recreation were analyzed. The strategies used by experimental literature to build truth on the discipline of Recreation are subjected to the separation between theory and practice, the backing up of the child's heteronomy and the simplification of reality.
\end{abstract}

Keyword: Recreation, Teaching, Leisure.

\section{Introdução}

Ao longo da história dos cursos de formação em Educação Física, duas perspectivas de trabalho aparecem de maneira bastante nítida quando se trata de recreação e lazer. De um lado encontramos aqueles profissionais que se auto-avaliam como sendo práticos e, de outro, aqueles que são sinalizados (principalmente pelos discursos dos primeiros) como sendo teóricos.

Essas duas perspectivas, de forma implícita, disputam a forma como deve ser orientado o discurso na área de recreação e lazer. Se analisarmos sob esse prisma, há uma relação de poder instituída e pouco debatida no cenário acadêmico. Numa perspectiva ou em outra, as bibliografias, os eventos e os cursos não se compatibilizam; cada um utiliza estratégias diferentes na elaboração de suas verdades. Podemos até dizer que o próprio nome da disciplina, em alguns casos, costuma direcionar a forma como ela deve ser interpretada. Geralmente, quando a disciplina recebe a denominação de recreação, ela está associada àquilo que se convencionou chamar de atividades práticas. Quando se denomina lazer, sua discussão está voltada para as análises mais gerais dessa problemática. E, naqueles currículos onde a disciplina se denomina recreação e lazer, há o predomínio da primeira sobre o segundo.

Essas regularidades acabam por constituir um conjunto de práticas que balizam aquilo que deve ser aceito como verdadeiro pelas comunidades acadêmicas. Cada discurso que se forma a partir desse quadro é ungido de um certo po- 
$\mathrm{der}^{2}$ para fazer com que seus enunciados sejam considerados verdadeiros, como também procuram desconstituir, negando-o ou endereçando-o como erro o discurso do outro.

Como observaremos ao longo do trabalho, aqui reside uma diferenciação de natureza epistemológica importante. Não entendemos a verdade como uma construção que deve ser equacionada através do debate sobre a relação entre o sujeito do conhecimento e o objeto a ser conhecido com vistas a encontrar a verdadeira essência das coisas. Dirigimos nossa atenção para as estratégias utilizadas nesse jogo de interesse entre grupos, para assinalar quem é que está autorizado a di-

\begin{tabular}{|c|c|}
\hline $\begin{array}{r}\text { Não entendemos a } \\
\text { verdade como uma } \\
\text { construção que deve } \\
\text { ser equacionada } \\
\text { através do debate } \\
\text { sobre a relação entre o } \\
\text { sujeito do } \\
\text { conhecimento e o } \\
\text { objeto a ser conhecido } \\
\text { com vistas a } \\
\text { encontrar a } \\
\text { verdadeira essência } \\
\text { das coisas }\end{array}$ & $\begin{array}{l}\text { zer a verdade ou quem } \\
\text { a possui. Desta forma } \\
\text { preferimos que esse } \\
\text { trabalho seja analisado } \\
\text { como um discurso que } \\
\text { procura rastrear uma } \\
\text { história política do } \\
\text { conhecimento na área da } \\
\text { recreação e lazer }{ }^{3} \text {. }\end{array}$ \\
\hline
\end{tabular}

rantir uma certa naturalidade e perenidade ao conhecimento, deslocando o debate para uma história interna da verdade ${ }^{4}$.

Portanto, nossa atenção está voltada para as estratégias pelas quais um determinado discurso de recreação é verificado para apresentar, seduzir e convencer os outros sobre a veracidade de seus enunciados. Consequentemente, na lógica de nosso trabalho, não faz sentido perguntarmos quem está com a verdade entre os diferentes discursos sobre a recreação e lazer. Queremos ape- nas compreender quais são as estratégias e práticas acadêmicas que fazem com que determinados discursos apareçam como sendo verdadeiros e outros, falsos.

Para dar conta dessa problemática, fomos buscar no referencial foucaultiano, principalmente nas suas reflexões sobre as relações entre poder e saber, os ingredientes para essa análise.

Como todos sabemos, o livro tem sido um aliado pedagógico importante dos professores na tarefa de ensinar. Nos últimos anos, um número cada vez maior de profissionais tem se dedicado a produzi-los. Se, por um lado, isso representa um acréscimo em nossa possibilidade de formação continuada, por outro, a literatura carece de contrapontos que tenham a finalidade de garantir a tensão crítica tão fundamental ao trabalho acadêmico.

Sendo o livro de recreação e lazer um espaço privilegiado para apresentar ou constituir determinadas verdades, sua análise apresenta-se como um campo profícuo na identificação dos diferentes projetos que gravitam nessa disciplina. Neste sentido, o objetivo deste trabalho foi identificar os pontos pelos quais os livros que sugerem atividades recreativas (chamaremos aqui de literatura de experimentação ${ }^{5}$ ) ancoram-se para justificar determinados procedimentos e referendar certas práticas acadêmicas como sendo verdadeiras.

Foram analisados vinte e dois livros direcionados para atividades de experimentação em recreação ${ }^{6}$ que estavam à disposição nas bibliotecas de três Faculdades de Educação Física ${ }^{7}$.

Para consecução do estudo, numa primeira parte, apresentaremos o corpo teórico que irá subsidiar a análise dos livros textos. Após faremos uma análise da literatura, centrando nossa atenção em alguns pontos que fragilizam a argumentação interna da literatura de experimentação e que abrem brechas para uma outra forma de pensar a prática pedagógica na disciplina de Recreação e Lazer. 


\section{Elementos para análise}

Uma prerrogativa importante do debate acadêmico é a possibilidade de visões distintas ou concorrentes exporem suas perspectivas para que elas também possam ser objetos de reflexões e críticas públicas. Como uma das intenções desse trabalho é projetar uma análise crítica sobre obras que subsidiam o trabalho de professores e alunos em processo de formação acadêmica, apresentaremos nossa linha de raciocínio na expectativa de que suas incompletudes, hiatos e simplificações possam permitir a amplificação do debate.

O principal motivo que deu origem à investigação, está relacionado ao poder que o livro na área de recreação tem sobre o planejamento da disciplina, principalmente quando queremos construir algumas estratégias de trabalho junto com os estudantes. E muito comum nos primeiros dias de aula dos Cursos de Educação Física assistirmos aos estudantes perguntando quando iniciam as aulas práticas ou quando irão aprender os joguinhos que aparecem nos livros de recreação. Esse fenômeno já havia sido percebido no estudo realizado por Valente (1997).

Diante de um contexto que apresenta um cenário distinto daquilo que é aceito pelo senso comum dos estudantes como sendo a recreação, eles costumam reivindicar a verdade anunciada pela literatura de experimentação. $\mathrm{O}$ constrangimento produzido por essa prática objetiva garantir, por um lado, uma certa unidade do conhecimento e, por outro, inibir o pensamento dissidente, divergente ou simplesmente diferente.

Em geral, esses livros costumam apresentar um conjunto de atividades para serem experimentadas no cotidiano. A tese principal é que as atividades ali expostas permitem a sua duplicação sem qualquer tipo de mediação com o cotidiano. E importante destacar que a maioria da literatura não faz qualquer tipo de ressalva em relação aos seguintes pontos: quem são as crianças, quais seus níveis de motivação e de desen- volvimento, quais os jogos que são desafiadores para elas, qual o papel do professor em suas aprendizagens e qual o nível de criação das atividades, estes tópicos não aparecem como questões relevantes nas obras analisadas.

O que está em jogo nesse debate é como são constituídos certos contextos que permitem sinalizar aqueles discursos que aparecem como verdadeiros (indepen-Essa realidade, um dentemente dos con- tanto quanto teúdos que eles ex- desconfortável para
pressão)

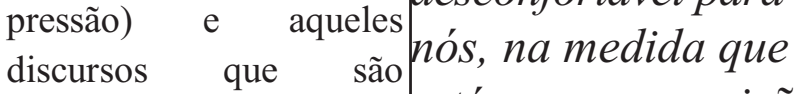
considerados falsos. Essa estávamos na posição realidade, um tantode anunciadores de quanto desconfortávelum discurso falso, para nós, na medida que nos exigiu interpretar estávamos na posição (se- esse contexto a luz de gundo os alunos) de um referencial que anunciadores de um permitisse fazer uma
discurso falso (por não sinalizarmos conteúdo aquilo como análise mais produtiva que está nos livros de experimentação), nos exigiu interpretar esse contexto à luz de um referencial que permitisse fazer uma análise mais produtiva. Foi nesse momento que nos aproximamos da literatura foucaultiana com o sentido de extrairmos de seu pensamento elementos para análise da relação entre o saber e o poder.

Para Foucault, é através das relações de poder que produzimos aquele conhecimento que deve aparecer como verdadeiro e aquele que será sinalizado como falso. Nenhum conhecimento pode ser considerado como verdadeiro sem poder, e nenhum poder pode ser constituído sem um tipo de saber. Não se trata de fazer do poder o lado negativo dessa relação e buscarmos no saber a alternativa para superá-lo. Foucault nos alerta que precisamos estar atentos, pois não há um saber redentor, idôneo capaz de desfazer as coerções ou 
más intenções do poder. Portanto, não podemos negar a existencia do poder nem sua força em constituir certos cenários como sendo verdadeiros a partir de algum tipo de saber. O que move o conhecimento é uma tensão permanente entre saber e poder na busca da constituição da verdade. Esta parece ser a própria dinâmica do conhecimento. A todo momento, estamos diante de verdades que são combatidas, negadas e superadas não por uma verdade verdadeira, mas sim por um novo saber produto de uma nova relação de poder também contextual, histórica e que será superada ali adiante.

Diante desse caso, talvez fosse mais prudente agirmos como um intelectual de oposição, pois como retrata Blacker (1990):

\section{"Em vez de esposar a verdade, o papel primeiro do intelectual de oposição deveria ser o de combater a forma pela qual ela é arbitrariamente manufaturada e disseminada (p. 164).}

Foi na história que a recreação se tornou um objeto possível de ser analisado, interpretado e descrito e, se o poder pode tomá-la como alvo de investigação, foi porque tornou-se possível desencadear estratégias ou técnicas de saber para produzir verdades. Portanto, iremos em direção a essa atmosfera para analisarmos as estratégias que permitiram - e permitem - constituir a recreação como uma disciplina que trata exclusivamente de atividades de experimentação, conforme demonstram os livros da área.

Como já dissemos anteriormente, são as relações de poder que permitem, através de práticas concretas, a constituição de regimes de verdade $^{8}$, ou seja, a delimitação daquilo que deve aparecer como verdadeiro e aquilo que deve ser sinalizado como falso em um dado momento e contexto histórico. Nesse sentido, não há produção de verdades desinteressada e livre. Toda a verdade está envolvida na produção de determinadas práticas que garantem o privilégio e o poder de grupos em poderem dizer aquilo que consta como verdadeiro.
Em nosso caso, a materialização desse discurso pode ser observada na reivindicação dos estudantes pedindo que a disciplina fosse "prática" em contraposição a uma que eles consideravam teórica. Por conseguinte, a verdade estaria do lado da prática e não da teoria.

Para fazer uma primeira provocação, poderíamos perguntar: quem duvida de que os livros de recreação não estão tratando de recreação? Há uma série de indícios que sim: a existência própria do livro como relacionado à área de recreação, de um corpo de profissionais que se propõe a produzir sobre essa área e um certo senso comum (compartilhado pelos estudantes) de que essa disciplina deve concentrar sua atenção nas atividades de experimentação, anunciadas como sendo atividades práticas. Compreender as estratégias utilizadas por esse regime de verdade para apresentar o que deve constar na disciplina de recreação e lazer torna-se um objetivo importante a ser seguido por aqueles que ministram essa disciplina.

\section{A continuidade entre senso comum e a disciplina de recreação.}

Uma das principais estratégias do regime de verdade que baliza o discurso dos livros de recreação, é a garantia da continuidade entre o entendimento, em nível do senso comum, sobre as atividades a serem realizadas, o conteúdo que é proposto pela literatura de experimentação. Talvez essa seja uma das estratégias importantes para seduzir o estudante de início de curso: não estabelecer uma cisão tão radical entre o discurso trazido por ele e aquele produzido pela academia.

Se, por um lado, isso pode ser uma estratégia pedagógica importante de aproximação do estudante, a permanência desse discurso em nível de senso comum constrói o alicerce na qual será investido o poder para determinar a verdade sobre o saber na área de recreação. 
Bento (1999), parafraseando Scheffler, alerta para os perigos de uma proposta de trabalho acadêmico alicerçada no senso comum:

\footnotetext{
" Apesar de reconhecimento do peso da tradição e senso comum, Scheffler advoga a necessidade de uma base cientifica para o ensino, de modo a que o professor possa julgar e escolher procedimentos na base de uma compreensão teórica, em vez de uma mera conformidade a receitas compiladas de sabedoria das gerações anteriores" (p. 194).
}

Uma primeira observação que podemos destacar diz respeito às regras internas para elaboração da literatura de experimentação. E comum esta literatura, produzida para professores, recreacionistas ou estudantes de terceiro grau, não apresentar suporte bibliográfico capaz de sugerir a fundamentação teórica de sua criação ou de onde surgiram tais atividades.

Não raro, nós vamos encontrar atividades de experimentação que aparecem em duas ou mais obras apenas com uma mudança de nome ou na sua organização interna sem que com isso seja expressa a fonte. Duas hipóteses são interessantes nesse caso: ou as atividades são colhidas no cotidiano das brincadeiras infantis ou elas foram copiadas de alguém sem apresentar a fonte.

Talvez esse posicionamento esteja relacionado à postura de alguns professores e valorizada de maneira incisiva pelos estudantes, de que trabalhar com recreação é trabalhar com a prática no seu sentido mais vulgar, como uma atividade que não precisamos ter critério e coerência.

Nesse quadro, teoria é interpretada como sendo algo desprendido do cotidiano, uma abstração. Essa postura acaba por sugerir uma crítica, muitas vezes caricaturada e grotesca, por parte daqueles que se propõem a fazer atividades de experimentação, de que seu trabalho não é produto de teoria e sim da prática.

Nesse caso, a prática surge como produto da geração espontânea, que se basta a si própria. Para essa concepção, caberia ao recreacionista uma postura passiva diante da prática, pois ela iria, sem qualquer custo ou esforço intelectual seu, constituir a verdade da recreação. Como o objetivo, nessas atividades, não é compreender como as crianças aprendem, para que elas se tornem autônomas e criativas, realizar atividade prática não passa de uma repetição mecânica de experiências motoras.

A premissa de que há um mundo prático parte do princípio (que é bastante primário) de que o dualismo teoria/prática é a única forma de compreendermos racionalmente o real ${ }^{9}$. Essa simplicidade costuma ser referendada quando se utiliza a sala de aula, sem as devidas considerações sobre a diferença entre o ambiente de laboratório, utilizado na formação inicial dos docentes, e o cotidiano como espaço de experimentação. Avessos à reflexão, os estudantes costumam experimentar essas atividades como se Perguntas do tipo fossem um ensaio, um "que reação as laboratório para as diferentes crianças
atividades esperam aplicar no poderiam ter frente cotidiano.

Perguntas do tipo "que reação as diferentes crianças poderiam ter frente a uma determinada atividade?" são substituí- de que a aula deve das pela necessidade satisfazer, construída/inventada de primeiramente, que a aula deve satisfazer, primeiramente, aos interesses de movimento dos qos interesses a uma determinada atividade?" são substituídas pela necessidade estudantes do terceiro \$rau grau. A aula boa é aquela em que eles se movimentaram bastante e não aquela em que eles aprendem como é que as crianças aprendem essas atividades; em nenhum momento eles se perguntam quais os diferentes 
constrangimentos que dificultam a participação de todos; em nenhum momento o olhar do observador (do professor) é posto em cheque, no sentido de ele deslocar a sua atenção para os níveis de aprendizagem de todos os estudantes e o seu papel no rompimento da heteronomia. Com isso, o trabalho dos professores costuma referendar práticas tradicionais no trabalho com crianças, como veremos na última seção desse estudo.

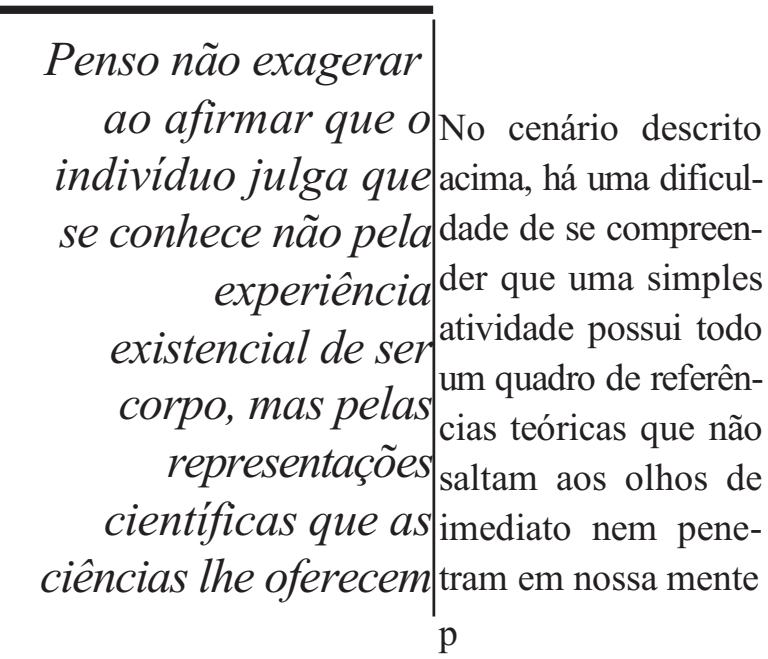

or osmose. Para compreendê-la, teríamos que olhar a prática como produto de uma ação reflexiva, tarefa essa que exigiria um esforço intelectual negligenciado e secundarizado nas obras analisadas. Para Bento (1999):

"Pensar praticamente, procurar a ação adequada a cada situação particular, é a expressão imediata dessa racionalidade prática, constituída e constituinte de conhecimento experimental que emana da reflexão na ação"(p.195).

Procurando focalizar a problemática do papel do professor no jogo infantil, enquanto um agente de reflexão teórico-prática, Negrine (1994) ressalta que:

"(...) tudo parece indicar que o adulto deve estar preparado para fazer a leitura do jogo da criança, interpretar seu significado simbólico e, em alguns casos, quando utiliza o jogo como ferramenta de trabalho, também para implicar-se no jogo e, dessa forma, alavancar o desenvolvimento da criança." (p.13).

Analisando o papel do professor na construção de atmosferas interessantes e desafiadoras para as crianças, De Vries (1991, p.7) sugere que:

"(••) será muito útil ao professor que ele considere o que aqueles desafios significam do ponto de vista teórico (discutidos no terceiro capítulo). Só assim, unindo teoria e a prática, o professor poderá constituir um trabalho cada vez mais profundo e equilibrado, com jogos relevantes para o desenvolvimento das crianças."

Para nós, a teoria é um conjunto de proposições oriundo da ação cotidiana que orienta e dá direção a essa mesma atividade. Nesse sentido, não interpretamos a atividade prática como possuindo existência em si, algo que exista fora de nossas intenções, e a teoria como pura abstração. Essa postura anula a possibilidade de compreendermos, como sinaliza Negrine (1994), o significado simbólico do jogo para as crianças ou, como faz Kamii e DeVries (1991), as diferentes variáveis que interferem na aprendizagem do jogo. Sem a articulação dessas duas dimensões não será possível diferenciar o profissional de Educação Física do não profissional.

As evidências nos apontam para uma continuidade entre a concepção de prática existente no cotidiano das pessoas comuns e aquela compartilhada pelos autores dos livros de experimentação em recreação. Para aqueles que estão absortos no cotidiano, o mundo teórico, entendido como abstração, não é um porto seguro para desenvolver atividades práticas. Não é difícil ouvirmos dessas pessoas que a teoria na prática não funciona. Daí resulta a total negligência e falta de preparo para interpretar o universo teórico/ prático em que estão imersas as atividades.

Ao duvidar da teoria, em nenhum momento aqueles que estão no cotidiano se perguntam que teoria é essa que se propõe a abarcar a prática em toda a sua complexidade de forma a lhe sufocar, a lhe arrancar a possibilidade do novo e da transformação? Que prática é essa que não pode ser compreendida como produto e objeto da teoria, de uma análise mais sistemática e sofisticada? Que 
relação há entre a divulgação desse discurso prático no campo acadêmico e a estruturação de cursos paralelos à formação de recreacionistas que se propõem unicamente a apresentar atividades práticas, fáceis de serem consumidas?

Sem compreendermos os interesses que permitem que determinados discursos interfiram nas ações e nas práticas pedagógicas no âmbito da recreação, será impossível analisarmos a sua vontade de verdade (de poder).

"(...) essa vontade de verdade, como os outros sistemas de exclusão, apoia-se sobre um suporte institucional: ela é ao mesmo tempo aprofundada e renovada por uma quantidade de práticas como a pedagogia, ê claro, como o sistema dos livros, da edição, das bibliotecas, como as sociedades sábias de outrora, os laboratórios de hoje. Mas ela é renovada também, mais profundamente sem dúvida, pela maneira pela qual o saber e posto em ação na sociedade, pela qual ele é valorizado, distribuído, repartido e, de alguma maneira, atribuido. (...) Assim, aparece aos nossos olhos apenas uma verdade, que seria riqueza, fecundidade, força doce e insidiosamente universal. E nós ignoramos, em compensação, a vontade de verdade, como prodigiosa maquinaria destinada a excluir." (Foucault, 1993, p.5).

Os livros analisados apresentam um inventário bastante significativo de atividades de experimentação de fácil assimilação. O problema reside principalmente no seu caráter instrumental. Como apoio didático, eles não fazem observações capazes de conduzir o leitor a compreender os limites e a complexidade das atividades ditas prática. Ao reproduzi-las os alunos correm o risco de repetirem as simplificações, exclusões (trataremos desse tema mais adiante) e injustiças e erros que encontramos nesses manuais.

Na atividade $O$ Semáforo de Fritzen (1985, p. 16) a relação que as crianças deverão fazer sobre a sinalização é inversa àquelas exigidas pelo Código Internacional de Trânsito. No vermelho, elas deverão continuar, no verde elas deverão parar e quem errar deverá sair da atividade. Quem produz uma atividade dessa, confia que quem o irá ler e reproduzir não tem nenhuma capacidade de autodeterminação, apenas é um copista.

Acreditamos que o motivo principal para essa realidade está relacionado ao desprezo aos subsídios teóricos. A sua ausência reflete, em se tratando de um trabalho realizado por professores, de uma negação esquizofrênica da teoria, alegando a autosuficiência da prática. Diante desse realidade, é muito comum os textos apresentarem algumas contradições e discursos fantasiosos que poderiam ser evitados com uma análise séria e criteriosa.

Um paradoxo importante que encontramos ao rastrear essa literatura é que a noção de prática que esses autores têm não passa de uma abstração, de uma idéia que não tem repercussão no real. As atividades de experimentação não passam de uma idéia abstrata do que sejam as crianças e seus comportamentos em sala de aula. Como exigir criatividade, descontração e prazer - Jm paradoxo discurso anunciado natmportante que parte introdutória de \&ncontramos ao quase todas as obras rastrear essa literatura analisadas - apresentando \& que a noção de atividades onde as prática que esses crianças passam, a maior quutores têm não passa parte do tempo, uma atrás de utra, à espera de sua le abstração, de vez para realizar a ıma idéia que não tem atividade determinadarepercussão no real pelo professor? O que faz com que essas crianças respeitem tal determinação?

Essas atividades só podem dar certo se nós eliminarmos aquilo que há de mais infantil na criança: sua espontaneidade, seu comportamento incerto, sua rebeldia e reforçarmos sua heteronomia. No pátio, eliminamos as cadeiras e as classes, mas garantimos sua imobilidade através do discurso da ordem, travestido de atividade recreativa ou de garantia do direito de todos à 
brincadeira. Metaforicamente, nós poderíamos dizer que as crianças, nesses livros, estão sem vida, mortas. O que permanece de vivo é apenas a idéia - aqui sim, pura abstração do que sejam seus comportamentos, suas aprendizagens e seus interesses. Portanto, não há nada de real nessas propostas. Ao final, restaria apenas um inventário de atividades, algumas até criativas, para serem exploradas, pensadas e não aplicadas de imediato.

Como podemos observar, as bases para a elaboração de trabalhos de experimentação em recreação serão considerados verdadeiros quanto mais simples forem suas análises, para ficar ao alcance do senso comum, e quanto mais nós pudermos reforçar a tese de que ser prático é não ser teórico. A inversão desse raciocínio (numa superação aos maniqueísmos cartesianos ${ }^{10}$ ) implicaria no esfacelamento completo dessa perspectiva.

\section{0 real: uma brincadeira sem graça}

Nesta seção, iremos explorar algumas passagens dos livros analisados que consideramos estratégicas para apresentar os pontos pelos quais a verdade desses manuais procuram se ancorar. Importante salientar que os pontos selecionados de maneira intencional não são discursos isolados, mas sim fazem parte de todo um conjunto de práticas que tem por finalidade garantir a configuração de um determinado quadro como verdadeiro. Eles foram selecionados para reforçar aquilo que procuramos criticar nessas obras.

Inicialmente nossa avaliação busca analisar a forma como a área da recreação é concebida nos livros. Em nosso estudo, constatamos que dificilmente os trabalhos apresentam um conceito claro que ultrapasse aquele que consta nos dicionários. Para Toseti, "A palavra recreação vem do latim, recreare, cujo significado é recrear. Portanto as atividades recreativas devem ser espontâneas, criativas e nos trazer prazer"' (s/d, p.14).
Como as obras não objetivam fundamentar o que entendem por recreação, elas deixam brechas enormes entre aquilo que anunciam, mesmo que superficialmente, e aquilo que aparece no corpo do trabalho. Para exemplificar, apresentaremos a [ seguinte passagem do trabalho de Fritzen (1987): j "E nos momentos de maior desinibição de relax, I de descontração, oferecidos pelos jogos e brincadeiras que as pessoas desbloqueiam e se descontraem e se realiza uma aproximação maior, uma melhor integração" (p.9). Mais adiante, na atividade Maria Ordena, ele diz que : "Se o animador mandar fazer alguma coisa, sem dizer também Maria Ordena, ninguém deverá atender. Caso isto aconteça, aquele que o fizer, sairá da brincadeira." (p-42).

Os verbos mandar e sair e o comportamento que o animador deve seguir nas duas atividades apresentadas desse autor não são compatíveis com o que é anunciado anteriormente. O exemplo contradiz completamente aquilo que é apresentado no início do trabalho.

Freqüentemente o discurso da recreação também vem associado a palavras como liberdade de expressão, criatividade, prazer e espontaneidade. A função desses discursos é despistar o leitor das contradições existentes em suas propostas. Esses discursos não passam de práticas pedagógicas dissimuladoras ou de encenação para direcionar a atenção do leitor aos aspectos mais românticos das obras, inscritos nas palavras alegria, criatividade e prazer.

Como podemos observar em Ferreira (1999), o texto discursa liberdade de expressão e é o professor que escolhe o que deve ser feito e diz quando termina.

"Cada grupo escolhe um integrante de cada vez. O escolhido ficará de pé no centro da sala, falando sem parar sobre um assunto determinado pelo professor. Ganha aquele que falar mais tempo sobre o assunto determinado pelo professor sem interrupções, no tempo determinado por ele. "(p. 15). 
Um outro detalhe mais preocupante nessa atividade é que o professor poderá escolher temas que coloquem em situações desconfortáveis aqueles alunos que tenham dificuldades de falar em público ou que talvez tenham pouco a dizer sobre o assunto escolhido por ele. Aqui, o choque de culturas poderá trazer conseqüências ainda mais danosas à criança se o professor escolher um tema distante das vivências dos alunos.

Discursam participação e apresentam atividades onde quem for pego ou errou o primeiro exercício fica de fora ou é penalizado.

"Se o aluno se confundir ou errar, poderá pagar com uma pequena corrida" (Silva, 1997, p. 15). Aqui a competição é carregada de uma conotação negativa, à medida que aquele que errou terá que se expor publicamente através de uma atividade que não tem nada a ver com a competição. Para Kamii (1991), "Quando os adultos lidam de maneira errada e destrutiva com a competição, ela se torna altamente indesejável." (p.272).

Discursam motivação, mas não criam critérios de equiparação dos rendimentos para que as disputas possam ser mais equilibradas, dando condições a todos de ganharem e não apenas os mais habilidosos nas competências do jogo que o professor escolheu.

"Em decúbito ventral, passar a corda no peito dos pés e segurado com as duas mãos. Tentar elevar o máximo os pés e as mãos. Vence a melhor performance." (Moreno, 1997, p.182).

Para nós, esse último elemento, a performance, é o que mais os professores de Educação Física têm dificuldade de lidar. Por desconhecerem ou por não analisarem as habilidades que contribuem de maneira decisiva no desempenho das atividades propostas, sejam elas recreativas ou não, os professores acabam por reforçar preconceitos e impedir que as crianças valorizem a diversidade das performances existentes em cada coletivo ao vivenciarem atividades de competição. Os mais fracos, os mais gordinhos, as meninas, os que possuem alguma deficiência, que na maioria das vezes sequer participam dos jogos, e as meninas negras principalmente, sob o manto da pretensa democracia racial existente no Brasil, são os últimos a serem escolhidos e os primeiros a serem condenados pelos fracassos. Acabam acusados, em rituais públicos ou pelo olhar, de serem os responsáveis pela derrota da equipe no jogo ou por terem errado. Nem os conflitos, muito comuns a uma sociedade complexa, nem as formas de inter-vençãos apresentadas para que Os mais fracos, os ocorram aprendizagens mais gordinhos, as baseadas em outros meninas, os que princípios de convi-possuem alguma vência. Os livros agem deficiência, que na como se isso não fizesse maioria das vezes parte da realidade, como se isso fosse uma ficção. sequer participam dos jogos, e as Quando anunciam as meninas negras habilidades que serão principalmente, são desenvolvidas, apresentam uma taxinomia ultrapassada. E escolhidos e os muito comum nos textos primeiros a serem aparecerem determinadas atividades fracassos desenvolvem a coordenação, a sociabilização ou a afetividade sem que esses conceitos tenham sido previamente trabalhados e detalhados. Com isso, essas palavras se tornaram expressões de um discurso vazio, repetidos sem nenhum sentido.

Nesse caso, uma pergunta interessante a fazer é: como tratar da coordenação de maneira abstrata se para diferentes atividades nós teremos diferentes arranjos neuro-musculares e, portanto, diferentes coordenações? Se todas atividades exercitam algum arranjo neuro-muscular não precisamos citar, a todo momento, que ela, a coordenação, é objetivo de todas atividades. Esse exemplo pode 
ser explorado com outras palavras (sociabilização, afetividade) que são anunciadas em muitos desses manuais, mas não dizem como se dão essas aprendizagens nem como nós as avaliamos.

Os trabalhos, que apresentam uma rápida passagem pelas questões teóricas ou que simplesmente não as apresentam, conduzem o leitor a uma relação puramente instrumental com as atividades, alimentando a consciência comum de um certo preconceito à dimensão teórica. Os trabalhos de Orso (1998, 1999), Santos (1998), Ferreira et ali (1993, 1999), Moreno (1997), Silva $(1996,1997,1998)$, Pimentel (1996), Civilate (1999) e Fritzen $(1985,1987)$ são as expressões desse princípio de trabalho.

Nesse sentido, as atividades apenas apresentam um roteiro utilitarista que poderia ser seguido por qualquer pessoa que estivesse à frente de um grupo de crianças. O perigo dessas propostas é que o leitor apressado ou desavisado pode acreditar que basta ter alguns conhecimentos práticos das atividades (uma bagagem extensiva de brincadeiras) que eles alcançarão objetivos, muitas vezes apresentados de maneira simplória, como por exemplo: o jogo ou a brincadeira são integrantes indispensáveis do desenvolvimento infantil. Toda e qualquer brincadeira? De que maneira uma brincadeira pode levar a uma postura positiva frente a uma determinada atividade? Essas questões não podem ser dribladas, esquivadas. A renúncia a esse debate apenas desnuda a falta de competência em discutir esse tema de uma maneira mais profunda.

Nesse caso, trabalhos como o deNegrine (1994) e Kamii \& DeVries (1991) são importantes à medida que apresentam uma densa discussão sobre o papel do jogo no desenvolvimento infantil. A partir do que sugere esses atores, é possível nós estabelecermos metas mais objetivas e claras no trabalho com crianças. Fora desse quadro teórico, as atividades estão desprovidas de qualquer possibilidade mais séria de colaborarem com o desenvolvimento infantil, principal- mente porque negligenciam o papel do professor nesse processo.

Esse parece ser um outro ponto em que as obras, aqui analisadas, não conseguem encontrar uma explicação razoável. Para minimizar essa problemática alguns autores costuma substituir a expressão professor por orientador, animador ou até educador. Alguns autores acreditam que esse deslocamento dará uma nova virtude ao profissional que irá trabalhar com recreação. Esta postura nominalista serve apenas para justificar algo que as obras não conseguem fazer através da abordagem de seus conteúdos.

Infelizmente, nesses manuais, o papel do professor se choca frontalmente com aquilo que é dito como ato de recrear: espontaneidade, prazer e criatividade. Há poucos espaços para a criação e a espontaneidade nas atividades apresentadas, pois as atividades reforçam a heteronomia.

Outra palavra que deixa em posição desconfortável os autores é a competição. Apesar de apresentarem atividades onde existe o confronto de equipes com objetivos opostos, a palavra competição é seguidamente desconsiderada. Para muitos, há uma oposição entre recreação e competição e uma índole má na primeira. Kamii \& DeVries (1991) interpretam que os professores costumam ter um sentimento dúbio em relação às atividades onde ocorrem competições e isso dificulta sua utilização no desenvolvimento infantil.

"Após descobrirem seu par, as crianças se abaixarão de mãos dadas. 0 último par ou dupla a se encontrar será considerado perdedor. Os alunos perdedores não deverão ser eliminados da atividade. 0 nosso objetivo não é destacar apenas os vencedores. Podemos criar critérios para não restringir (eliminar) os alunos do jogo. Por exemplo: cada aluno recebe um crédito de dez pontos. Ao invés de ser eliminado, ele vai perdendo pontos. Se ele perder os dez pontos, ele passa a ajudar na organização do jogo. O importante é manter participando do início ao fim da atividade" ${ }^{\prime \prime \prime}($ Santos, 1998, p.78). 
Esse exemplo traduz a nossa preocupação. Primeiro, o professor elabora um jogo onde há alunos que deverão ser "eliminados" e ele não sabe o que fazer com essas crianças. Segundo, só trabalha a partir da lógica de perdedores e ganhadores, sem enfrentar o problema da competição no desenvolvimento infantil. Por último, propõe um critério que somente prolonga o tempo de atividade daquele que deverá sair, sem garantir uma solução adequada àqueles que perderam os dez pontos. Tendo em vista seu desempenho, os excluídos do jogo são levados a uma posição de auxiliares do professor como se esse fosse o objetivo da atividade.

Para Kamii (1991):"Os adultos devem lidar com a competição mais naturalmente, para que a criança também veja o fato de ganhar como nada mais do que ganhar. Sua glorificação coroa o ganhador com um sentimento de superioridade e o perdedor com um sentimento de falha. Quando os adultos lidam de maneira errada e destrutiva com a competição, ela se torna altamente indesejável." (p.272).

Mais adiante ela destaca:

"Para Piaget, o desenvolvimento de habilidades de competir em jogo acompanha o desenvolvimento da habilidade de descentração e coordenação de ponto de vista" (p.274).(...) "0 dever do professor não é evitar jogos competitivos, mas guiar as crianças quanto a esse desenvolvimento, para que elas se tornem jogadoras justas e capazes de comandar a si próprias" (p.281).

Desconsiderar essas reflexões faz parte da estratégia para construir a verdade de que a competição interfere de maneira negativa no desenvolvimento infantil. Os que costumam sugerir uma abordagem mais elaborada recebem a tacha de teóricos. Assim, fica fácil constituir a distinção e anunciar quem está com a verdade prática.

Diferentemente das abordagens utilitaristas, o trabalho que nos chama a atenção é o de Constance Kamii \& Retha DeVries, Jogos em grupo na educação infantil: implicações da teoria de Piaget. Em cada uma das atividades experimen- tadas e comentadas são apresentadas as possibilidades de entendimento do aluno, a partir do seu desenvolvimento motor, social, moral, emocional, político e cognitivo, a sua percepção frente aos conflitos, o olhar do professor diante desse contexto e as alternativas possíveis para a solução dos problemas. Aqui, teoria e prática produzem uma realidade que se distancia do utilitarismo da literatura de experi- Aqueles trabalhos que
mentação. Essa obra é um mentação. Essa obra é um se propõem a necessário para aqueles desenvolver atividades que desejam compre- recreativas no âmbito ender a profundidade e a da escola não dão a complexidade do trabalho devida atenção aos com recreação e jogos aspectos pedagógicos
com crianças.

Para nós, o papel importante do professor nas atividades recreativas é atuar no processo educativo que envolve o jogo. Nesse caso, Negrine (1994) faz uma avaliação preocupante: o professor não estuda com profundidade o componente simbólico do jogo. A falta de referencial teórico ou de observações sobre os aspectos relacionados com a aprendizagem do jogo, nos trabalhos por nós analisados, apenas reforçam essa tese.

Um outro ponto também problemático é a relação entre a recreação como meio ou como fim no trabalho desenvolvido pela Educação Física na escola. Aqueles trabalhos que se propõem a desenvolver atividades recreativas no âmbito da escola não dão a devida atenção aos aspectos pedagógicos. Parece existir um jogo de dissimulação. Primeiramente são apresentados alguns discursos desarticulados e sem consistência teórica que criticam a Educação Física, a escola e, logo após, as atividades aparecem como respostas às preocupações anunciadas.

Algumas perguntas poderiam ser feitas para explorar esse debate. Se há autores que sinalizam que só se joga, no sentido de recrear-se, de ma- 
neira autônoma, por que o professor administra a atividade o tempo todo? Como trabalhar com espontaneidade se os objetivos são estabelecidos pelo professor? Como ficam os interesses dos alunos e o seu papel frente a determinadas obrigações como, por exemplo, ficar em fila? O que fazer com os interesses divergentes? O que fazer com o prazer de algumas crianças que são constrangidas, através do professor ou de uma pretensa democracia, a participarem de atividades que eles não gostariam? Como interagir diante das relações de gênero? Quais as implicações do currículo oculto nas atividades? Como de-

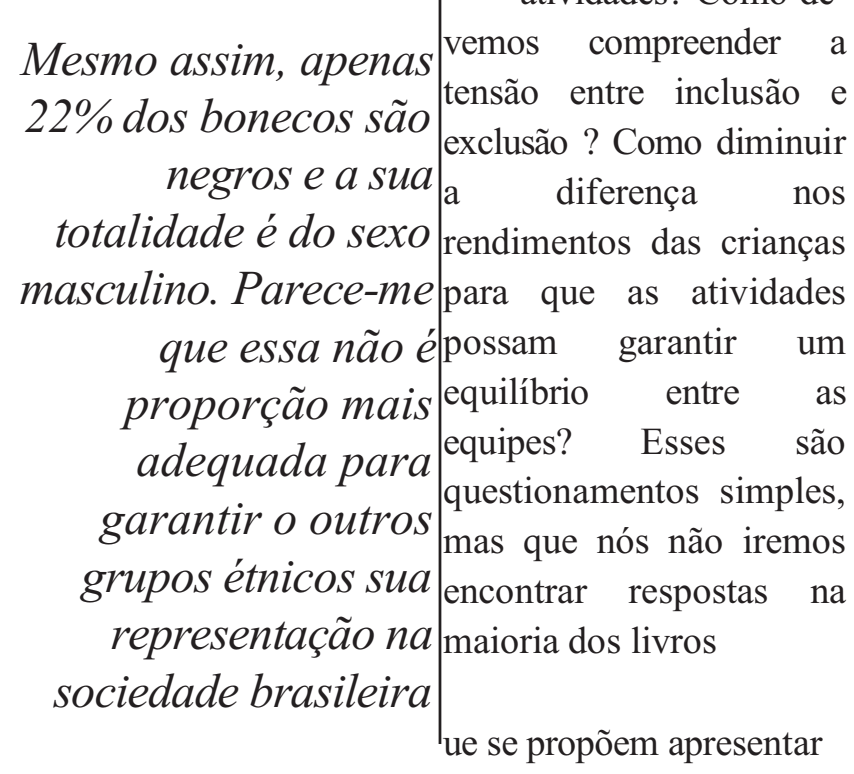
atividades de experimentação às crianças.

O trabalho de Orso (1999) chega a esboçar, de uma forma muito superficial, essa conexão: " $A$ escola está cada vez mais séria, propondo arrancar habilidades especificas dos alunos. Nela só restou o recreio como um local de trocas, de afeto e de brincar. O recreio, por sua vez, está pobre e sem conteúdo." (p.8).Mais adiante ele acrescenta: "Diante dessa realidade, torna-se importante a valorização do brincar, (...)" (p.8).

Na obra citada, o conceito de brincar não é apresentado em nenhum momento. Como não está explícito em seu trabalho o papel que ele atribui a Educação Física, nós podemos deduzir que essa disciplina teria um papel importante na transformação desse quadro. Por outro lado, as atividades contidas no livro apresentam uma estrutura rígida incompatível com a idéia de brincar, de recrear. Em diversas atividades, nós iremos encontrar as crianças em filas, exercitando uma de cada vez, com uma inspiração mecanicista que é capaz de produzir inveja àqueles professores classificados de tecniscistas ou comportamentalistas. Diferentemente da ludicidade anunciada, as atividades dependem diretamente da intervenção do professor.

Seguindo a classificação criada por Faria Jr. (1982), o estilo por comando, de inspiração tecnicista, deixa pouco espaço para criação:

$$
\begin{aligned}
& \text { "E um estilo de ensino onde o professor ê o elemento } \\
& \text { humano preponderante, com um papel bem defini- } \\
& \text { do. E ele que determina os objetivos da aula, escolhe } \\
& \text { as atividades, fornece as indicações precisas sobre o } \\
& \text { que executar" (p.53). }
\end{aligned}
$$

Orso (1999) também elimina toda a complexidade que envolve o recreio ao apresentá-lo como local de trocas. Análises recentes têm demonstrado que há relações de poder que impedem que esse espaço possa ser plenamente usufruído por $\operatorname{todos}^{11}$; portanto, está longe de alcançar os objetivos por ele assinalado.

Outros dois exemplos são sugestivos para essa análise. No trabalho de Guerra (1984), uma das atividades é pular corda. Em nenhum momento a autora faz qualquer comentário sobre os elementos que podem garantir o sucesso e o insucesso dos alunos na atividade. $\mathrm{O}$ que fazer com aqueles alunos que interpretam essa atividade como exclusiva do sexo feminino? Como garantir uma boa excitação a todos se alguns não conseguem saltar tanto quanto gostariam? Qual o papel do professor frente a essas dificuldades? Essas perguntas são fundamentais para o desenvolvimento dessa atividade no contexto escolar e que não têm resposta na obra.

Em Santos (2000), vamos encontrar toda uma 
seqüência pedagógica que teve a preocupação de garantir patamares mínimos de desempenho motor para que as crianças pudessem participar em condições mais equilibradas, com grande satisfação e criatividade do ensino do pular corda. Sem o domínio dessa competência, as crianças estariam desenvolvendo uma atividade que apenas reproduziria sua desigualdade de acesso a essa aprendizagem.

Em seis trabalhos analisados, não encontramos sequer referências bibliográficas. Decorre dessa constatação três hipóteses: ou esses trabalhos são produtos de um ato de criação próprio desses autores, ou fazem parte do conhecimento de todos, ou as atividades são copiadas de outros autores e não se quer apresentar a fonte.

A primeira hipótese parece pouco sustentável, na medida em que algumas atividades aparecem em mais de um autor com apenas algumas variações como, por exemplo, corrida do ovo e corrida da batata. $\mathrm{O}$ que muda nas atividades é apenas o que vai ser colocado em cima da colher. No segundo caso, nós iremos encontrar uma outra problemática. Se essas atividades fazem parte da memória coletiva da sociedade, e que em alguns casos atravessam séculos, como as brincadeiras de pegar, por que os trabalhos não explicitam, nas suas introduções, que a proposta do livro é apenas coletar ou arquivar aquelas atividades presentes no cotidiano lúdico da sociedade? Nesse sentido, as obras teriam muito mais uma finalidade histórica, de preservação da memória do que a pretensão de contribuir com o desenvolvimento infantil. A última hipótese, a menos provável, por isso pretendemos não discutir, representa uma limitação intelectual que não colabora para a valorização desse campo de conhecimento.

A taxinomia utilizada para distribuição das atividades também não oferece um horizonte seguro para a estruturação de uma proposta de trabalho. Há propostas como pequenos jogos moderados, calmos e grandes jogos. Parece que, em muitos casos, o objetivo é estabelecido para con- trolar a criança e não para lhe garantir um desenvolvimento criativo. Como explicar que crianças de oito anos tenham que fazer atividades de aquecimento se elas chegam na aula ansiosas, esbaforidas e contagiadas com a possibilidade de realizar atividade na rua? Elas correm, saltam, vibram, se mexem como se estivessem na aula mais importante. Que compreensão de criança e de escola é essa que consta nos livros? Realizar jogos calmos no final das aulas é para satisfazer as crianças ou para adequar o corpo àquela concepção expressa nas paredes e ambientes da escola?

O último ponto de nossa avaliação está relacionado ao simbolismo expresso nas representações gráficas contidas nos livros. Em vários trabalhos, não encontramos desenhos explicativos das atividades que possam orientar melhor o entendimento da dinâmica do jogo. Em outros, encontramos situações problemáticas do ponto de uma visão multicultural de identidade.

Em apenas um trabalho (Moreno, 1997) nós encontramos desenhos capazes de anunciar outro contexto étnico diferente daquele do branco. Mesmo assim, apenas 22\% dos bonecos são negros e a sua totalidade é do sexo masculino. Parece-me que essa não é proporção mais adequada para garantir o outros grupos étnicos sua representação na sociedade brasileira. Deixar de mencioná-los faz parte dessa racionalidade preconceituosa que posou na mente de homens e mulheres, alguns até de boa vontade, e que já causou grandes estragos à humanidade.

Concordamos com Silva (2000) quando discute quem é que tem o poder de definir a identidade ou a diferença:

"Não se trata, entretanto, apenas do fato de que a definição da identidade e da diferença seja objeto de disputa entre grupos sociais assimetricamente situados relativamente ao poder. Na disputa pela identidade estão envolvids outras disputas mais amplas por outros recursos simbólicos e materiais da sociedade. A afirmação da identidade e a anunciação da diferença traduzem o desejo de diferentes grupos sociais, 
assimetricamente situados, de garantir o acesso privilegiado aos bens sociais. (...) A identidade e a diferença nao sao inocentes" (p.81)

Nos demais trabalhos ocorre uma situação ainda pior. Os personagens são assexuados, para não dizer figuras que lembram o sexo masculino, e não existe a preocupação de incluir outros personagens de raça ou outras normalidades. Esse exemplo, aliado ao processo brutal de exclusão da raça negra, dos portadores de necessidades especiais às políticas de visibilidade dos livros didáticos, das revistas, dos programas de televisão, apenas corroboram para a continuidade das injustiças produzidas pela sociedade brasileira. Os livros aparecem e parecem como se não tivessem nada a ver com isso. Esse conformismo com o instituído é o pior exemplo que esses trabalhos dão aos estudantes de Educação Física.

No trabalho de Constance Kamii \& Retha DeVries (1991) nós iremos encontrar um cuidado muito especial com essa problemática. Há uma riqueza étnica que complementa a perspectiva filosófica e ética apresentada anteriormente. A responsabilidade intelectual da obra é produto de uma elaboração sofisticada e engajada.

Outra análise interessante pode ser realizada com as taxinomias: desafios individuais, confronto de duplas, confronto de grupos, circuitos recreativos e atividades pelas idades. Como todo o processo de classificação, esta estratégia, principalmente quando não explicada de forma consistente, sugere uma separação que não pode ser compreendida dentro de outras perspectivas de análise. Se o processo de construção motora é produto também dos aspectos culturais, qual é a lógica de distribuí-los por idades? O que determina que um jogo é moderado se numa sala de aula nós vamos encontrar diferenças orgânicas na resposta ao exercício? Por que os jogos com bola não podem ser considerados como jogos de corrida? Por que apresentar jogos adequados ao sexo? Os autores não expressam (e não podem expressar) com clareza o que querem com essas classificações.
Essas questões são fundamentais para que nós possamos inscrever as atividades no contexto pedagógico da escola. As atividades jamais poderão ser qualificadas como propostas não problemáticas. Sem discutirmos o que queremos com nossos alunos, não basta oferecer-lhes atividades que, pedagogicamente, podem fazer um movimento contrário àquilo que acreditamos ser importante para sua formação. A não observância dessas questões apenas desnudam a resistência desses livros em acompanharem as discussões mais recentes no campo pedagógico.

Os pontos explorados aqui da literatura de experimentação abrem uma brecha importante para analisarmos o conteúdo que as obras anunciam como sendo verdadeiro e aquilo que é possível de se pensar sobre essas verdades.

\section{Considerações finais}

Uma das estratégias que utilizamos para desenvolver esse trabalho foi desconstituir uma certa idéia sobre a verdade que não permite pensarmos a diversidade nem criticarmos aquilo que um determinado grupo de professores anuncia como sendo uma verdade universal.

Ao selecionarmos a literatura de experimentação, nosso objetivo era compreendermos quais as estratégias utilizadas para garantir força de verdade a seus enunciados. Entre os principais estão: instituir um discurso e um debate que não ultrapasse os limites do senso comum; produzir discursos fantasiosos sobre a recreação para desviar a atenção daquilo que é efetivamente proposto enquanto atividade; não apresentar conceitos claros sobre os principais temas apresentados; despir as atividades de toda a complexidade que envolvem as aprendizagens, para que sua assimilação seja fácil; constituir uma certa identidade estética, em relação às imagens valorizadas pela cultura hegemônica; garantir a participação do professor como personagem central na adminis- 
tração das atividades recreativas, reforçando a heteronomia das crianças.

Sem os pontos apresentados, não é possível compreendermos como os livros de experimentação podem estar relacionados a determinadas verdades sobre a recreação. A fragilidade desse discurso também representa a fragilidade da própria comunidade acadêmica de propor alternativas que superem a simplicidade e a simplificação que dão sustentação a esse regime de verdade.

Esperamos que esse trabalho possa sugerir reflexões que permitam a construção, a constituição ou a invenção de uma outra proposta para o ensino da recreação nas Faculdades de Educação Física baseados em outros critérios acadêmicos no trato com o conhecimento.

\section{Referências Bibliográficas}

01. ALMEIDA, Paulo Nunes de. Educação lúdica. São Paulo: Edições Loyola, 1990.

02. ATLAN, Henri. Com razão ousem ela: intercrítica da ciência e do mito. Tradução Fátima Gaspar e Carlos Gaspar. Lisboa: Instituto Piaget, s/d.

03. BECKER, Howard S. Métodos de pesquisa em Ciências Sociais. 3 ed. Tradução de Marco Estevão e Renato Aguiar. São Paulo: Ed. Hucitec, 1997.

04. BENTO, Jorge Olimpo, Garcia, Rui e Graça, Amândio. Contexto da pedagogia do desporto: perspectiva e problemas. Lisboa: Livros Horizontes, 1999.

05. BLACKER, David. Foucault e a responsabilidade intelectual. In.: Silva, Tomaz Tadeu da. (Org.) O sujeito da educação: estudos foucaultianos. Petrópolis: Vozes, 1994. p.155-172.

06. CAVALLARI, Ricardo Vinícius e ZACHARIAS, Vany. Atividades para quadras, salões e espaços de médio porte. São Paulo: ícone, 1998.
07. CIVILATE, Héctor. Jogos recreativos: para clubes, academias, hotéis, acampamentos, spa e colônias de férias. Rio de Janeiro: Sprint, 1999.

08. DE VRIES, Retha. Bons jogos em grupo: o que são eles? In: KAMII, Constance \& DeVries, Retha. Jogos em grupos na educação infantil: implicações da teoria de Piaget. Tradução de Marina Célia Dias Carrasqueira. São Paulo: Trajetória Cultural, 1991. p.3-12.

09. FARIAS Jr., Alfredo Gomes, Corrêa, Eugênio da Silva e Bresane, Roselaine da Silva. Práticas de ensino e educação física: estágio supervisionado. Rio de Janeiro: Ed. Interamericana, 1982.

10. FERREIRA, Solange Lima et ali. Recreação. Rio de Janeiro, 1993.

11. , Solange Lima. Atividades recreativas para dias de chuvas. Rio de janeiro: Sprint, 1999.

12. FOUCAULT, Michael. Microfísica do poder. Tradução Roberto Machado. Rio de janeiro: Edições Grall, 1979.

13._ Michael. História da Sexualidade I: a vontade de saber. Tradução de Maria Thereza da Costa Albuquerque e J. A. A. Guilhon Albuquerque. $7^{\circ}$ ed. Rio de janeiro: Edições Grall, 1985.

14. , Michael. A ordem do discurso. Campinas: Unicamp, 1993. (mímeo).

15 , Michael. A verdade e as formas jurídicas. Tradução Roberto Machado e Eduardo Jardins Morais. Rio de Janeiro: Nau Ed., 1999.

16. FRITZEN, Sílvio José. Dinâmica de recreação e jogos. Petrópolis: Vozes, 1985.

17.___ Sílvio José. Jogos dirigidos: para grupos, recreação e aulas de educação física. Petrópolis, RJ: Vozes, 1987.

18. GUEDES, Maria Herminia de Souza. Oficina da brincadeira. Rio de Janeiro: Sprint, 1998.

19. GUERRA, Marlene. Currículo por atividade: recreação e lazer. Porto Alegre: Sagra, 1984. 
20. KAMII, Constance. A questão da competição. In: KAMII, Constance \& DeVries, Retha. Jogos em grupos na educação infantil: implicações da teoria de Piaget. Tradução de Marina Célia Dias Carrasqueira. São Paulo: Trajetória Cultural, 1991. p. 269-285.

21. KAMII, Constance \& DeVries, Retha. Jogos em grupos na educação infantil: implicações da teoria de Piaget. Tradução de Marina Célia Dias Carrasqueira. São Paulo: Trajetória Cultural, 1991.

22. KHUN, Thomas. A estrutura da revoluções científicas. São Paulo: Perspectiva, 1978.

23. MIRANDA, Nicanor. 200 jogos infantis. Belo Horizonte: Editora Hatiaia, 1983.

24. MORENO, Guilherme. Jogos e contestes. Rio de Janeiro: Sprint, 1997.

25 , Guilherme. Recreação 1000 exercícios com acessórios. Rio de janeiro: Sprint, 1998.

26. NEGRINE, Airton. Aprendizagem e desenvolvimento infantil. Porto Alegre: Prodil, 1994.

27. ORSO, Darci. Atividades recreativas: resgatando o prazer de brincar. 2 ed. Novo Hamburgo, 1998.

28 , Darci. Brincando, brincando se aprende. Novo hamburgo: Ed. Feevale, 1999.

29. PAIVA, Ione Maria R. de. Brinquedos cantados. Rio de Janeiro: Sprint, 1998.

30. PEREIRA, Maria Solange. Jogos na escola, nos grupos, na catequese. São Paulo: Paulinas, 1984.

31. PIMENTEL, Figueiredo \& Rebelo, Vitória. 268 jogos infantis. Belo Horizonte: Villa Rica, 1996.

32. RORTY, Richard. Relativismo: encontrar e fabricar. In.: Áureo, Antônio e Salomão, Waly. (Orgs.) Banco Nacional de Idéias: relativismo enquanto visão de mundo. Rio de Janeiro: Francisco Alves, 1994. P.115-134.

33. SANTOS, Carlos. Jogos e atividades lúdicas na alfabetização. Rio de Janeiro: Sprint, 1998.
34. SANTOS, Edmilson Santos dos. A corporeidade no recreio: por um espaço desportivo. In.: Santos, Edmilson Santos dos (Org.) Educação Física escolar: por uma cultura desportiva. Novo Hamburgo: Feevale, Porto Alegre: Sulina, 1998. P.146-151.

35. , Edmilson Santos dos. Infância, escola e o ensino do desporto. Revista Perfil. Ano IV, n. 4,2000 . P.50-57.

36. SILVA, Elizabeth Nascimento. Atividade recreativa na $1^{a}$ infância: 2 e 3 anos. Rio de Janeiro: Sprint, 1997.

37 , Elizabeth Nascimento. Recreação na sala de aula $1^{\mathrm{a}}$ a $4^{\mathrm{a}}$ série. Rio de janeiro: Sprint, 1996.

38. , Elizabeth Nascimento. Recreação e jogos. Rio de Janeiro: Sprint, 1997.

Silva, Tomaz Tadeu da (org.) Identidade e diferença.: a perspectiva dos estudos culturais. Petrópolis, RJ: Vozes, 2000.

39. TOSETI, Solange. A educação física. Erechim: Edelbra, s/d.

40. VALENTE, Márcia Chaves. Lazer e recreação no currículo de educação física. Maceió: Edufal, 1997.

\section{Notas}

${ }^{1}$ Prof. Ms. Edmilson Santos dos Santos é Professor da Faculdade de Educação Física do UNILASSALE e ULBRA.

${ }^{2}$ A concepção de poder utilizada neste estudo é extraída do pensamento foucaultiano e está definido no livro: Foucault, M. História da sexualidade I : a vontade de saber. Tradução de Maria Thereza da Costa Albuquerque. 7 ed., Rio de Janeiro: Edições Grall,1985.

${ }^{3}$ Como nos apresenta Foucault (1999), referenciado em textos de Nietzsche: "(...) o conhecimento é, cada vez, o resultado histórico e pontual de condições 
que não são da ordem do conhecimento. (...) o conhecimento é sempre uma certa relação estratégica em que o homem se encontra situado. É essa relação estratégica que vai definir o efeito de conhecimento e por isso seria totalmente contraditório imaginar um conhecimento que não fosse, em sua natureza, obrigatoriamente parcial, oblíquo, perspectivo" (p. 23 - 24).

${ }^{4}$ Foucault (1999) diz que há duas histórias da verdade. A história interna da verdade é aquela que é produzida pela história da ciência onde existem princípios lógicos a serem perseguidos pelo discurso.

${ }^{5}$ A literatura de experimentação é aquela que apresenta um inventário de atividades para serem desenvolvidas no dia-a-dia.

${ }^{6}$ Diante da dificuldade de expressar uma linha coerente na seleção dos textos ou uma justificação que diminua o poder da subjetividade, concordamos com Becker (1997) quando diz que a melhor alternativa nesses casos é expor com clareza nossos pressupostos para que possam ser controlados de forma crítica pelos outros. Não houve nenhum critério de exclusão a priori. Selecionamos todos aqueles trabalhos que se direcionavam ao público infantil que se encontravam na biblioteca de três instituições de ensino superior e que foram produzidos de 1980 até 2000.

${ }^{7}$ Os livros foram encontrados nas bibliotecas das faculdades de Educação Física da Ulbra, La Salle e Ufrgs. Como a intenção do estudo é repensar a prática acadêmica na área da recreação, fomos atrás daquelas bibliografias que estão à disposição dos estudantes em suas faculdades.

${ }^{8}$ Ampliamos a noção de regime de verdade da obra de Foucault não restringindo a uma análise sobre os paradigmas que orientam a sociedade. Para Foucault (1979), "cada sociedade tem seu regime de verdade, sua política geral de verdade, isto é, os tipos de discurso que ela acolhe e faz funcionar como verdadeiros" (p.12).

${ }^{9}$ Rorty (1994): "Temos que admitir que essas distinções já fazem parte do senso comum ocidental, mas isto não é argumento suficiente para que as mantenhamos!" (p.1 19).

${ }^{10} \mathrm{O}$ plural se refere ao duplo maniqueísmo: colocar a prática como a expressão mais fiel do todo ou resumir a complexidade do real a uma dimensão unificadora, como fazem os que confiam em grandes síntese.

${ }^{1}$ Santos (1998) observou que, no recreio, os espaços são distribuídos a partir de uma lógica que privilegia os mmeninos mais fortes, altos, velhos, das turmas mais adiantadas. 
